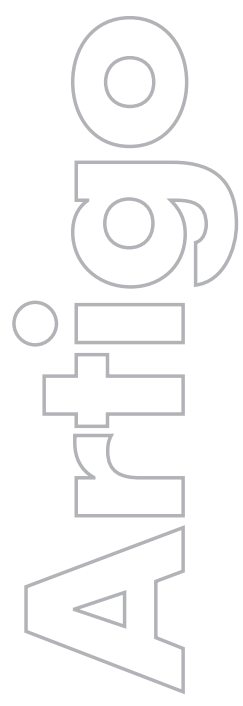

revista

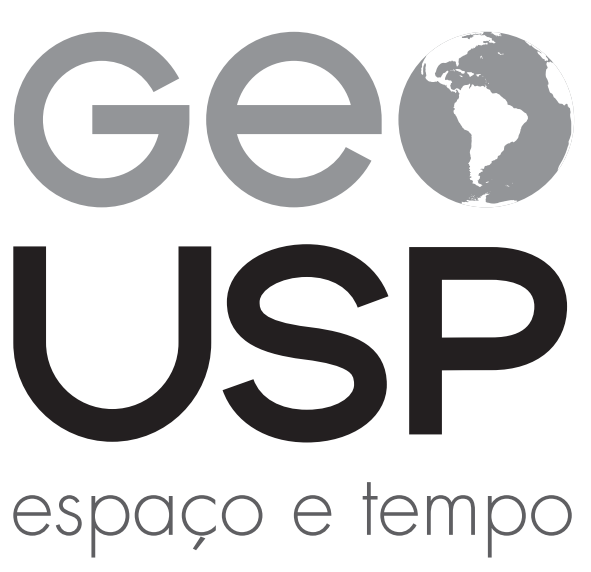

Volume $20 \cdot n^{\circ} 1(2016)$

ISSN 2179-0892
Corporeidade: sexualidades no mercado sexual transnacional sob o olhar eurocêntrico

\author{
Joseli Maria Silva \\ UEPG \\ Marcio Jose Ornat \\ UEPG
}

p. $69-82$

Como citar:

SILVA, J. M.; ORNAT, M. J. Corporeidade: sexualidades no mercado sexual transnacional sob o olhar eurocêntrico. Geousp - Espaço e Tempo (Online), v. 20, n. 1, p. 69-82, mês. 2016. ISSN 2179-0892.

Disponivel em: http://www.revistas. usp.br/geousp/article/ view/98302. DOI: http://dx.doi.org/10.11606/issn.2179-0892. geousp.2016.98302.

\section{(c) $(1)(9)$}

Este artigo está licenciado sob a Creative Commons Attribution 4.0 License. 


\title{
Corporeidade: sexualidades no mercado sexual transnacional sob o olhar eurocêntrico
}

\section{Resumo}

Este artigo procura compreender como a corporeidade e a sexualidade das brasileiras é produzida sob o olhar hegemônico eurocêntrico, bem como a capacidade subversiva das prostitutas, no processo de mobilidade espacial, de desenvolver estratégias para tirar vantagem de uma estrutura de forte exclusão e vulnerabilidade, contemplando uma perspectiva interseccional entre classe, gênero e raça. Para isso, fizeram-se quatorze entrevistas em profundidade com mulheres brasileiras profissionais do sexo residentes na Espanha, com idade entre 23 e 30 anos e seis entrevistas com homens espanhóis com idade entre 35 e 62 anos, assíduos frequentadores de locais em que se desenvolvem atividades de comércio sexual.

Palavras-chave: Mulheres brasileiras. Prostituição. Corporeidade. Mercado sexual transnacional.

\section{Corporeality: sexualities in the transnational sexual market under eurocentric gaze}

\begin{abstract}
The aim of this article is to understand how the corporeality and sexuality of Brazilian women are produced under the hegemonic Eurocentric outlook, as well as examining the subversive capability of prostitutes, who develop strategies to take advantage from a structure that is strongly exclusionist, and which forces these women into a position of vulnerability in Spain. The approach that has been adopted is an intersectional perspective that considers class, gender and race. To achieve this goal, 14 in-depth interviews were conducted with female Brazilian sex workers, aged from 23 to 30, and six interviews with Spanish men aged between 35 and 62, who regular customers of locations where commercial sex activities took place.
\end{abstract}

Keywords: Brazilian women. Prostitution. Corporeality. Transnational sex trade. 


\section{Introdução}

A porta se abre e aparece um belo sorriso de uma senhora de aproximadamente sessenta anos de idade. Perguntou-nos se éramos a pessoa indicada para a vaga de empregada doméstica e dissemos que sim. Convidou-nos a entrar e imediatamente começou a nos mostrar os cômodos de seu apartamento de quatro quartos, ao mesmo tempo em que falava sobre as demandas do trabalho que ela oferecia. Limpar, cozinhar, lavar e passar para seus três filhos homens adultos, ela mesma e ainda sua mãe, uma senhora mais velha que requeria cuidados especiais. Ofereceu um salário abaixo do mínimo pago na Espanha, justificando as despesas que ela teria com o acolhimento de mais uma pessoa em sua casa, já que o trabalho exigia dormir no emprego devido à necessidade de cuidados noturnos com sua mãe. Antes de sairmos, a senhora ainda alertou: "Não me importa que sejam ilegais; sei das dificuldades das brasileiras. Se você não falar bem o espanhol, não há problema. $\bigcirc$ importante é compreender muito bem aquilo que nós dizemos para você. Outro ponto é que, com três filhos homens em casa, é você quem tem que saber se comportar como uma pessoa de respeito, para que não haja qualquer tipo de problema, você entende?" (Trecho de diário de campo, Madri, 31 maio 2008).

Esse trecho do diário de campo de pesquisa é o registro de uma experiência compartiIhada com Cassiopeia, ${ }^{1}$ uma prostituta ${ }^{2}$ brasileira vivendo em Madri, numa de suas tentativas de abandonar a atividade comercial sexual e, segundo ela, "levar uma vida honesta, já que seus filhos estavam crescendo e logo saberiam o que ela realmente fazia para ganhar a vida na Espanha". Ao sair do apartamento, houve alguns minutos de silêncio. A revolta inundava os pensamentos e a voz daquela senhora; apesar de branda, ela exprimia toda a violência colonial com que o pensamento eurocêntrico ainda julga e valora as mulheres da América Latina. Além da aviltante exploração do trabalho, em suas palavras, dois elementos se destacavam: o corpo feminino colonizado entendido como ameaça à ordem e o silenciamento como normalidade das relações de poder instituídas. Enquanto alguns pensamentos intelectuais feministas faziam aumentar a indignação em torno dessa experiência, Cassiopeia disse, com toda sua sabedoria: "Acho melhor ser puta, mesmo! Como puta, me sinto mais importante aqui!" Nos olhamos, rimos com cumplicidade e concordei plenamente com ela.

objetivo deste texto é compreender como a corporeidade e sexualidade das brasileiras é produzida sob o olhar hegemônico eurocêntrico, bem como a capacidade subversiva das prostitutas, no processo de mobilidade espacial, em desenvolver estratégias capazes de tirar vantagens de uma estrutura de forte exclusão e vulnerabilidade, contemplando uma perspectiva interseccional entre classe, gênero e raça.

1 Esta reflexão jamais seria possível sem a generosidade e a inteligência de Cassiopeia, uma brasileira, profissional do sexo que vive em Madrid e se tornou uma grande amiga, com quem dividi conhecimentos, aventuras e, acima de tudo, muito afeto e admiração. Todos os nomes dados no texto são fictícios.

2 Há uma disposição geral do Ministério do Trabalho, bem como de direitos humanos globais para o uso de expressão "profissionais o sexo". O grupo DAVIDA, organização brasileira que luta por direitos cidadãos de pessoas que comercializam práticas sexuais, preferem a palavra "prostituta" e reivindicam sua ressinificação. As mulheres com quem convivi em Madri se diziam "putas". Nesse sentido, procurando respeitar os diferentes posicionamentos, adotaram-se várias palavras e expressões, de acordo com o contexto. 
Este texto está baseado em uma pesquisa realizada em 2008 sobre a imigração ilegal de brasileiras para o mercado sexual na Espanha. ${ }^{3}$ Em Madri, conheci Cassiopeia (autor 1), uma brasileira profissional do sexo, com quem acabei desenvolvendo profundos laços de amizade que perduram até os dias de hoje. A partir dela, durante oito meses em que vivi em Madri, passei a fazer parte de suas redes de relacionamentos, composta de outras brasileiras prostitutas, seus clientes, amigos e namorados.

Assim, foi possível uma aproximação singular com este universo em que foram realizadas quatorze entrevistas em profundidade com mulheres brasileiras profissionais do sexo, com idade entre vinte e três e trinta anos e seis entrevistas com homens espanhóis com idade entre trinta e cinco e sessenta e dois anos, assíduos frequentadores de locais em que se desenvolvem atividades de comércio sexual. As mulheres brasileiras relataram ter terminado o nível médio de escolaridade, ter baixa renda no Brasil e serem mães. Entre os homens entrevistados, 66,7\% alegou ter nível educacional superior e 33,3\% o nível médio. Todos eles se identificam como pertencentes a uma camada de média renda na Espanha. Além disso, foram realizadas observações de campo em quatro clubes de alto padrão que oferecem serviços sexuais em Madrid.

Os eixos de investigação do roteiro de entrevistas exploraram as representações das mulheres brasileiras na sociedade espanhola e sua atuação no mercado sexual. As entrevistas foram transcritas na íntegra e interpretadas por meio de análise de conteúdo (Bardin, 1977).

Na primeira parte do texto será explorada as representações hegemônicas criadas em torno das mulheres brasileiras na Espanha, marcadas pela exotização de sua nacionalidade naquele contexto. Na segunda parte são exploradas as representações criadas pelas mulheres brasileiras profissionais do sexo que, reconhecendo o espaço de exclusão e marginalidade, criam formas de subverter sua condição social e econômica naquele país.

\section{Tropicalização sob o olhar hegemônico: a presença das brasileiras na Es- panha e a geopolítica do desejo}

As primeiras décadas do século XXI têm sido marcadas por um aprofundamento das discussões em torno dos deslocamentos transnacionais envolvendo gênero, sexualidades e interesses econômicos. $\bigcirc$ Brasil é um dos países globalmente reconhecidos como origem de fluxos de pessoas para os chamados países centrais, de que se destacam Portugal e Espanha (Fernandes; Nunan, 2008; Masanet; Padilla, 2010). Os dados do Instituto Nacional de Estatística da Espanha (INE) de 2010 apontava que a imigração brasileira era majoritariamente feminina, composta de 60,9\% de mulheres e 39,1\% de homens. ${ }^{4}$ Além disso, o agravamento da crise econômica nos países europeus receptores de populações, bem como o acirramento das políticas anti-imigratórias, têm pressionado cada vez mais o governo brasileiro a atuar contra os deslocamentos transnacionais para fins sexuais. ${ }^{5}$

3 Os oito meses de trabalho de campo foram realizados em conjunto. Enquanto um de nós (autor 1) investigava as redes estabelecidas na Espanha, o outro (autor 2) explorava as conexões dessas redes no Brasil.

4 Em 2010, os dados do INE apontam 146.941 imigrantes brasileiros vivendo na Espanha.

5 Em 2006, a Secretaria Nacional de Justiça, do Ministério da Justiça, em conjunto com a Secretaria de Direitos Humanos (SDH) e da Secretaria de Políticas para as Mulheres (SPM), elaboraram a Política Nacional de Enfrentamento ao Tráfico de Pessoas. Em 2008, o Ministério da Justiça instituiu o primeiro Plano Nacional de Enfrentamento ao Tráfico de Pessoas e, em 2011, foi lançado o segundo plano. 
O debate em torno da mobilidade internacional promovida pelo desejo, sexualidade e vantagens financeiras envolvendo o Brasil despertou o interesse de pesquisadores como $\mathrm{Pe}$ lúcio (2010, 2011, 2012), Piscitelli (2006, 2007, 2009) e Piscitelli, Assis e Olivar (2011). A intensificação das políticas de combate ao tráfico de pessoas, tanto no Brasil como nos países receptores de fluxos de pessoas provenientes de países periféricos, tem chamado a atenção dos meios de comunicação, que apontam os deslocamentos transnacionais para fins sexuais como perigosos e criminalizados, gerando várias polêmicas sobre tal processo (Grupo Davida, 2005; Hynes; Raymond, 2002; Kempadoo; Sanghera; Pattanaik, 2005; Schauer; Wheaton, 2006).

A imprensa é um importante instrumento na criação e circulação de ideias hegemônicas sobre determinados temas e grupos sociais. As brasileiras na Espanha, bem como em Portugal, estão presentes na imprensa daqueles países em dois sentidos: pelo casamento entre mulheres brasileiras e homens portugueses e espanhóis e pela prostituição de brasileiras exercida naqueles países. Os anúncios na imprensa sobre a prestação de serviços sexuais são marcados pela nacionalidade brasileira, que aparece como um importante atributo comercializável. ${ }^{6}$

Os nomes adotados pelas profissionais do sexo em seus anúncios fazem alusão direta à nacionalidade brasileira, e sua imagem corporal explora cores e símbolos nacionais. Além disso, são verificadas ainda notícias sobre brasileiras como vítimas de "tráfico de seres humanos". Nas notícias sobre matrimônio e prostituição, destacam-se a capacidade "natural" de sedução das brasileiras e sua corporeidade.

Em 2010, em matéria publicada na revista portuguesa Focus, destacam-se na capa um corpo feminino com um biquíni com as cores da bandeira brasileira e o seguinte subtítulo: "Os segredos das brasileiras. Adoradas pelos homens, odiada pelas mulheres, o facto é que as brasileiras fazem sucesso e entre as estrangeiras são as quem mais casam com portugueses [...]" (Focus, 2010, p. 116). Em 2011, outra revista portuguesa, Activa' publicou a matéria "Afinal, o que é que a mulher brasileira tem que nós não temos?" (Fonseca, 2011), comentando o livro Os segredos das mulheres brasileiras: para manter os homens loucamente apaixonados, que dá uma série de "dicas" sobre como usar das habilidades das brasileiras para atrair e conquistar os homens. $\bigcirc$ livro apresenta a seguinte sinopse:

Quem não ouviu já falar do incrível poder de sedução das mulheres brasileiras? Do seu jeitinho especial de ser e de estar? Da sua forma carinhosa de falar e de dar mimo? Do cuidado que têm com a aparência e o corpo? Da maneira como "enlouquecem" os homens? São muitas as mulheres em todo o mundo que morrem de ciúmes sempre que uma brasileira entra em cena. Que se sentem inseguras, receando que os seus parceiros se encantem por elas... Vamos ser sinceras: na maioria dos casos, têm mesmo razão para ter medo. É que as brasileiras são mesmo "gostosas" e tentam facilmente o sexo oposto! Mas é importante perceber que elas são assim por natureza [...] (Wook).

Outra matéria, veiculada na BBC em 2009, abordava a presença maciça de brasileiras na Espanha e sua inserção naquela sociedade pelo casamento com homens espanhóis: "As brasileiras lideram as preferências dos homens espanhóis entre as estrangeiras na hora de casar" 
(Infante, 2009). A presença das mulheres brasileiras na Espanha promove "zonas de contato" em que as pessoas têm diferentes posições de poder (Pratt, 1991). Além da desvantagem das condições materiais das mulheres brasileiras que majoritariamente compõem o mercado laboral em serviços domésticos e de hotelaria mal pagos, como apontam Fernandes e Nunan (2008), elas também têm desvantagem na produção de discursos sobre sua própria realidade e sobre sua posição como sujeitos colonizados (Spivak, 1988; Hooks, 1990).

A situação de invisibilidade das mulheres latino-americanas e os discursos hegemônicos produzidos sobre elas na Espanha foi investigada por Echezarrieta e Leyva (2008). Segundo elas, a enunciação hegemônica da sociedade espanhola caracteriza-se a si mesma como "avançada", "trabalhadora", "racional", "moderna", "democrática" e "igualitária”, enquanto representa as mulheres latino-americanas a partir de uma noção de oposição, criando o usual imaginário de oposição "self/other" (Said, 1979).

A produção discursiva sobre as mulheres latino-americanas na Espanha produz a ficção política em que elas estão envolvidas e que justifica a ação colonizadora sobre elas. Aparício e Chávez-Silverman (1997, p. 8, tradução nossa) criam o conceito de tropicalização, ${ }^{7}$ que:

[...] é uma figura discursiva para imbuir um determinado espaço, geografia, grupo ou nação de um conjunto de traços e imagens. Esses discursos entrecruzados são distribuídos em textos oficiais de história, na literatura e nos meios de comunicação, circulando, assim, essas construções ideológicas através de vários níveis da sociedade receptora. [...] $\bigcirc$ tipo de tropicalização que estamos considerando aqui seria uma ideia mítica da latinidade com base nas projeções anglo de medo (ou dominante). Ele está intrinsecamente ligado à história das agendas políticas, econômicas e ideológicas dos governos e das instituições sociais. ${ }^{8}$

A tropicalização envolve as relações de poder e a posição do sujeito que enuncia o discurso hegemônico, mas, segundo Aparício e Chávez-Silverman (1997), uma representação produzida a partir da perspectiva do "tropicalizado" produz um potencial tanto de assimilação quanto de subversão. Danielson (2009) afirma que a consciência da forma como as imagens dos sujeitos tropicalizados são usadas pelos diferentes grupos pode servir tanto para propagar a hegemonia como para transformar o sujeito e suas condições de subalternidade.

Para avançar além da dicotomia entre tropicalizações hegemônicas e subversivas, este texto apresenta outras formas de relação de forças, envolvendo interseções entre diferentes categorias identitárias, o que complexifica as relações de poder e a organização de tensões entre sujeitos. $\bigcirc$ discurso hegemônico da sociedade espanhola sobre as mulheres brasileiras, por exemplo, não é hegemônico no que diz respeito ao gênero, pois homens e mulheres têm diferentes experiências com as brasileiras, podendo criar alianças ou oposições.

7 Os autores se valem da noção de orientalismo, de Said (1979), para construir analogamente a ideia de tropicalization.

8 " [...] means to trope, to imbue a particular space, geography, group, or nation with a set of traits, images. These intersecting discourses are distributed among official texts, history, literature, and the media, thus circulating these ideological constructs throughout various levels of the receptor society. [...] the sort of tropicalization we are considering here would be a mythic idea of latinidad based on Anglo (or dominant) projections of fear. It is intricately connected to the history of political, economic and ideological agendas of governments and social institutions" (Aparício; ChávezSilverman, 1997, p. 8). 
Echezarrieta e Leyva (2008) discutem a noção de latinidade construída pelo olhar dominante das mulheres espanholas em relação às mulheres imigrantes, procedentes da América Latina. Segundo as autoras, as mulheres espanholas produzem um discurso claro de racialização das mulheres latinas para "naturalizar" as relações assimétricas de poder e a inferioridade das latinas em relação às espanholas. As mulheres latino-americanas são descritas como "submissas", "procedentes de países subdesenvolvidos", "pobres", "hipersexualizadas", "atrasadas", "dóceis" e "exercem reprodução/maternidade descontrolada", indocumentadas.

O discurso produzido pelas mulheres espanholas sobre as mulheres latinas apontado por Echezarrieta e Leyva (2008), ao ser comparado com os resultados das entrevistas realizadas com homens espanhóis, evidencia algumas convergências de ideias entre os gêneros sobre as representações das mulheres latinas, mas também oposições. É justamente das oposições de ideias entre homens e mulheres espanhóis que as brasileiras encontram fissuras nas estruturas de poder naquele contexto que as possibilitam conquistar algumas vantagens, que serão tratadas na segunda seção deste texto.

O quadro que segue evidencia que os homens espanhóis também constroem a ideia da docilidade, hipersexualidade e pobreza sobre as mulheres brasileiras. Contudo, seu olhar sobre tais características da feminilidade das brasileiras é complementar à construção da ideia de sua masculinidade, diminuindo as tensões em torno da imigração e da rejeição. Quando questionados sobre a presença das mulheres brasileiras na Espanha, os homens trazem o tema da crise econômica europeia e de sua posição anti-imigração, mas isso não se refere às mulheres: "Que os homens vão embora, mas que fiquem as mulheres brasileiras [...]!" (Apolo, 54 anos, espanhol, tradução nossa). ${ }^{9}$

\section{Quadro 1 - Discurso dos homens espanhóis sobre si mesmos e as mulheres brasileiras}

\begin{tabular}{|l|l|l|}
\hline $\begin{array}{l}\text { categoria discursiva } \\
\text { (\% dos enunciados) }\end{array}$ & $\begin{array}{l}\text { nós (homens espanhóis) } \\
\text { atributos }\end{array}$ & $\begin{array}{l}\text { elas (mulheres brasileiras) } \\
\text { atributos }\end{array}$ \\
\hline sexualidade (35\%) & $\begin{array}{l}\text { necessidade/instinto biológico/ } \\
\text { natureza }\end{array}$ & $\begin{array}{l}\text { quentes/liberais/disponíveis/sentem } \\
\text { prazer/sabem o que fazer para agradar } \\
\text { um homem }\end{array}$ \\
\hline corporeidade (30\%) & sem referência direta & $\begin{array}{l}\text { bonitas/sensuais/atraentes/bunda } \\
\text { grande }\end{array}$ \\
\hline $\begin{array}{l}\text { imigração para prosti- } \\
\text { tuição (21\%) }\end{array}$ & $\begin{array}{l}\text { maior oferta de serviços sexu- } \\
\text { ais/variedades/novidades }\end{array}$ & $\begin{array}{l}\text { superação miséria/pobreza/ possi- } \\
\text { bilidade de ascensão/ajuda familiar/ } \\
\text { situação passageira }\end{array}$ \\
\hline afetos (14\%) & carência/solidão/insatisfação & $\begin{array}{l}\text { carinhosas/doces/sensíveis/generosas/ } \\
\text { mentirosas }\end{array}$ \\
\hline
\end{tabular}

fonte: Entrevistas realizadas entre fevereiro e setembro de 2008 em Madri, com seis homens assíduos frequentadores de locais em que se desenvolvem atividades de comércio sexual na Espanha.

9 "Que se vayan los varones, pero que se queden las mujeres brasileñas [...]!" 
Os enunciados dos discursos dos homens espanhóis sobre as mulheres brasileiras estão estruturados de forma relacional. A sexualidade de si mesmos é representada por eles como algo instintivo, uma necessidade e de outro lado, as mulheres brasileiras são consideradas disponíveis para o sexo e "quentes".

Outro eixo discursivo muito enunciado pelos homens espanhóis é a corporeidade, totalmente atrelada positivamente às mulheres brasileiras e inexistente no discurso desenvolvido sobre eles. A ausência da discussão de sua própria corporeidade está pautada na posição masculina de agente ativo na definição e caracterização dos "outros" corpos, enquanto seus próprios corpos não são categorizáveis.

A imigração para a prostituição aparece no discurso masculino como uma fatalidade. A pobreza das brasileiras e sua busca em superar esta condição é uma representação que coloca os homens espanhóis em uma posição de "auxilio às mulheres necessitadas". Assim, ao mesmo tempo em que aliviam a conotação moral negativa de serem usuários de serviços sexuais, podem também desfrutar do desejo da diversidade corporal e práticas sexuais oferecidas pelas mulheres imigrantes. $\bigcirc$ trecho de entrevista ilustra esses argumentos:

Neste subcontinente, muitas pessoas vivem em absoluta miséria, e é muito comum uma familia ser composta de uma mulher com várias crianças - podem ser seus filhos ou sobrinhos -, e ela viver com um homem que não é o pai de seus filhos. É muito frequente nesses locais que as mulheres tenham seu primeiro filho aos 15 anos de idade. A prática do sexo nessas sociedades é mais desinibida, mais natural do que aqui na Europa. E, quando uma mulher dessas percebe que é atraente para muitos homens daqui, claro, querem usar disso para sair da miséria, e isso é normal (Ares, 51 anos, espanhol, tradução nossa)..$^{10}$

Os homens espanhóis justificam o uso de serviços sexuais, além da "necessidade natural", como forma de superar suas carências, que estão associadas ao fato de as mulheres espanholas não corresponderem a suas expectativas afetivo-sexuais. As mulheres brasileiras, consideradas carinhosas, sensíveis e doces, são consideradas complementares a essas necessidades.

Mesmo que o conteúdo discursivo de homens e mulheres da Espanha sobre as mulheres latinas tenham profundas coincidências, como é o caso dos atributos da hipersexualidade, pobreza e docilidade associada à submissão, há paradoxos que emergem a partir da posição do olhar de cada um dos grupos, que têm diferentes experiências com mulheres latinas (Sánchez, 2006).

A hipersexualidade, por exemplo, é um atributo negativo do ponto de vista das mulheres espanholas e positivo do ponto de vista dos homens, mesmo que ambos os grupos componham uma representação hegemônica e eurocentrada. A submissão, associada à docilidade aparece como um atributo de mulheres "atrasadas e tradicionais", no discurso das mulheres espanholas, enquanto os mesmos atributos, do ponto de vista dos homens, é extremamente positivo, associada à ideia de que "uma brasileira sabe como agradar um homem" (Hermes, 42 anos, espanhol).

10 "En este subcontinente, muchas personas viven en la absoluta miseria y es muy habitual que una familia esté compuesta por una mujer con varios hijos. Pueden ser sus hijos o sobrinos y vivir con un hombre que no es el padre de sus hijos. Es muy frecuente en estos lugares que las mujeres tengan su primer hijo a los 15 años. La práctica de sexo en esta sociedades es más desinhibida, más natural que aquí en Europa. Y cuando una de estas mujeres ve que es atractiva para muchos hombres de aquí, claro, quieren aprovecharse de esos para salir de la miseria y es normal". 
Os atributos que produzem as representações das mulheres brasileiras na Espanha, mesmo que sejam comuns entre homens e mulheres, adquirem diferentes sentidos. As experiências desenvolvidas entre cada grupo e as mulheres brasileiras vão ser elementos fundamentais na elaboração dos sentidos que se dá aos atributos.

Homens espanhóis usuários de serviços sexuais, por exemplo, experimentam um tipo de relação que tem eixos de interseção específicos como é o caso do desejo sexual. As interseções vivenciadas pelas mulheres espanholas na relação com as brasileiras pode ter outros eixos, diferentes daqueles vivenciados pelos homens.

Nesse sentido, a perspectiva interseccional já desenvolvida por Crenshaw (1991), Davis (2009), McCall (2005) e Nash (2008) deve ser mediada pela experiência concreta, como argumenta Sánchez (2006). Assim, mesmo mediadas por discursos hegemônicos que as marginalizam, as fissuras de poder são reconhecidas pelas mulheres brasileiras e usadas por elas.

\section{Tropicalização a partir das margens: "yes, we have bootys, pussies, ba- nanas, tamborines and bangles"}

Uma brasileira na Espanha não tem valor fora do clube. No clube, os meus clientes pagam cada minuto pra estar comigo. Fora, alguns ex-clientes me ligam e querem foder de graça. Nem mesmo me dão uma carteira de cigarros. E tem mais, é coisa comum o patrão de um restaurante ou bar querer foder de graça também, pra não te mandar embora. No final, dão calote no salário e ainda ameaçam você que vão te entregar para a imigração se a gente fizer barraco. Então, é no clube que minha boceta tem poder! [risos]. Esse corpinho, fora do clube, não vale nada aqui na Espanha. Mas, no clube... Ah! Lá, ser brasileira é uma vantagem e tanto! (Cassiopeia, 30 anos, brasileira).

Este trecho de entrevista evidencia o reconhecimento por parte das brasileiras das interseções entre classe, gênero e racialidade/nacionalidade e sua relação direta com o espaço. $\bigcirc$ espaço é um importante elemento da análise interseccional (Brown, 2012; McDowell, 2008; Valentine, 2007) capaz de criar vantagens ou desvantagens na composição das relações de poder.

A tropicalização hegemônica, marcada pelo estereótipo da mulher brasileira hipersexualizada, submissa e pobre, é permeada pelas ações das brasileiras que, mesmo mediadas pelo forte discurso colonial, desenvolvem capacidade de ação cultural, social e econômica, reconhecem as fissuras das estruturas de poder, agindo para subverter seu processo de marginalização. Assim, a tropicalização se faz para além da macronarrativa sobre a nacionalidade das mulheres brasileiras na Espanha, mas também pelas suas resistências e transgressões (Bhabha, 1990).

As mulheres brasileiras prestadoras de serviços sexuais na Espanha são tropicalizadas, mas também tropicalizam a sociedade receptora. Além disso, elas se autorrepresentam utilizando dos mesmos atributos encontrados nos discursos hegemônicos. Entretanto, usam destas representações hegemônicas como ferramentas de poder (Aparício; Chávez-Silverman, 1997). Os enunciados que apresentam os atributos sobre si mesmas, os homens espanhóis e as mulheres espanholas foram organizados em quatro categorias (Quadro 2): 


\section{Quadro 2 - Discurso das mulheres brasileiras sobre si e sobre os homens e mulheres da Espanha}

\begin{tabular}{|l|l|l|l|}
\hline $\begin{array}{l}\text { categoria discursiva } \\
\text { (\% dos enunciados) }\end{array}$ & $\begin{array}{l}\text { nós (brasileiras) } \\
\text { atributos }\end{array}$ & $\begin{array}{l}\text { eles (espanhóis) } \\
\text { atributos }\end{array}$ & $\begin{array}{l}\text { elas (espanholas) } \\
\text { atributos }\end{array}$ \\
\hline sexualidade (45\%) & $\begin{array}{l}\text { quentes/liberais/ } \\
\text { disponíveis/sentem } \\
\text { prazer }\end{array}$ & $\begin{array}{l}\text { promíscuos/liberais/ } \\
\text { efeminados/drogados/ } \\
\text { casados }\end{array}$ & $\begin{array}{l}\text { frias/reguladas/ } \\
\text { não sentem prazer/ } \\
\text { conservadoras/ } \\
\text { não acessíveis }\end{array}$ \\
\hline corporeidade (30\%) & $\begin{array}{l}\text { bonitas/educadas/ } \\
\text { elegantes/femininas/ } \\
\text { sensuais }\end{array}$ & $\begin{array}{l}\text { falta de higiene/atraen- } \\
\text { tes fisicamente }\end{array}$ & $\begin{array}{l}\text { masculinizadas/ } \\
\text { desleixadas/pouco } \\
\text { femininas }\end{array}$ \\
\hline afetos (18\%) & $\begin{array}{l}\text { carinhosas/doces/ } \\
\text { emotivas/generosas }\end{array}$ & $\begin{array}{l}\text { carentes/bobos/gentis/ } \\
\text { emotivos }\end{array}$ & $\begin{array}{l}\text { grosseiras/autoritárias/ } \\
\text { egoístas/racionais/ inte- } \\
\text { ressadas no dinheiro }\end{array}$ \\
\hline conjugalidade (7\%) & paixão/amor/doação & $\begin{array}{l}\text { respeito e estabilidade } \\
\text { social }\end{array}$ & $\begin{array}{l}\text { por estabilidade finan- } \\
\text { ceira e social }\end{array}$ \\
\hline
\end{tabular}

fonte: Entrevistas realizadas com 14 mulheres brasileiras, profissionais do sexo na Espanha, entre fevereiro e setembro de 2008.

As mulheres brasileiras captam as representações hegemônicas sobre sua sexualidade e corporeidade e, como profissionais do sexo, utilizam a tropicalização a seu favor. Green (2008) define a qualidade e o número de atributos de uma pessoa e faz uma correspondência erótica em outra pessoa de "capital erótico". A atração sexual envolve a erotização do corpo, sexo e afeto, que podem tomar inúmeras formas, dependendo do tempo, do lugar e dos grupos sociais que estão envolvidos na relação erótica. Sendo assim, não existe um único recurso erótico, mas diferentes configurações de organização do desejo em que os recursos são distribuídos em variadas proporções entre as pessoas envolvidas no jogo erótico.

A comparação das estruturas dos discursos evidenciadas nos quadros 1 e 2 manifesta similaridades de atributos associados às representações das brasileiras no que diz respeito a sua sexualidade e corporeidade. Os atributos dessas categorias perpassam tanto as representações das mulheres espanholas (Echezarrieta; Leyva, 2008) e homens espanhóis sobre as mulheres brasileiras, como as representações das mulheres brasileiras sobre si mesmas. Entretanto, nos grupos de homens e mulheres brasileiras os atributos são considerados positivos e no grupo de mulheres espanholas são negativos.

Assim, a valorização dos atributos eróticos associados a sua nacionalidade faz com que as mulheres brasileiras exagerem sua "brasilidade" em determinados lugares, como é o caso dos espaços de prostituição. No salão de um dos clubes observados na pesquisa, havia uma prostituta que vestia um top verde e amarelo, cores da bandeira brasileira, em que se lia "Made in Brazil" sobre os seios, numa clara indicação de que se tratava do corpo de uma brasileira. Segundo ela, "Esta roupa atrai os clientes; quando visto, ganho dinheiro feito água. É um atrás do outro" (Nereida, 25 anos, brasileira). 
Para se colocar em situação de vantagem nas relações sociais que estabelecem na Espanha, as brasileiras profissionais do sexo engendram discursos em que os homens e as mulheres espanhóis são representados de forma negativa ou oposta a si mesmas.

As brasileiras relatam práticas sexuais consideradas incomuns para seu universo cultural, a dependência química da cocaína como componente principal dos programas sexuais e a utilização intensiva de raros instrumentos eróticos. Mesmo que sejam escolhas dos clientes no uso do tempo do programa sexual, elas representam essas práticas de modo a desvalorizar a masculinidade dos clientes espanhóis, comparando-os com os brasileiros, como vemos neste relato:

Aqui os homens são muito drogados. No Brasil, eles pagam por sexo, se te pagam uma hora querem ficar fodendo. Aqui, fico quatro, seis horas com o cara, mas para cheirar cocaína, todo programa tem cocaína. Eles têm hábitos muito estranhos, esse negócio de usar aparatos de sexo, de dar o cu pra gente. Nossa, isso pra mim não é coisa de homem, sabe? Mas eles querem, então, minha boceta cria teia de aranha, faz tempo que não uso [risos] [...] (Lissa, 26 anos, brasileira).

Embora subestimem a masculinidade dos homens espanhóis, reconhecem seu poder econômico. Entretanto, consideram-se capazes de manipulá-los por meio de sua superioridade sexual, atribuindo-lhes as características de bobos e carentes. Elas afirmam usar representações hegemônicas sobre si para tirar vantagens econômicas, como vemos no seguinte trecho de entrevista:

Os homens aqui pensam que no Brasil nós vivemos na floresta amazônica, somos miseráveis. Então, faço aquela cara de mulher doce, desprotegida, e conto uma história triste sobre meus filhos, e eles me ajudam, sabe? Nossa! Quantos presentes já mandei para o Brasil, para minha família, que eles compram para me ajudar (Gaia, 26 anos, brasileira).

As mulheres brasileiras tropicalizadas compreendem as estruturas de poder e conseguem jogar com os atributos que marcam sua representação na sociedade espanhola, bem como identificam os espaços que lhe confere maior ou menor vantagem para acionar sua brasilidade, como é o caso dos espaços de prostituição. Mas além disso, relatam utilizar de suas representações como mulheres sensuais, quentes e fáceis para tirar vantagens em situações de interação com homens em outros locais da cidade, além dos clubes.

Por outro lado, as mulheres brasileiras escondem sua nacionalidade em lugares onde os mesmos atributos de sua corporeidade e sexualidade podem ser considerados desvantagens, tal como mostra Valentine (2007) quando discute a dinâmica espacial na análise da interseccionalidade.

Esse jogo está apoiado no reconhecimento de vantagens e desvantagens nas interações com homens e mulheres. As brasileiras reconhecem que os mesmos atributos que caracterizam sua corporeidade e sexualidade são vistas como positivas, pelo desejo erótico dos homens, e como negativas, pelas mulheres espanholas. Nesse sentido, relatam que em lojas, ruas, restaurantes, em que interagem com mulheres, procuram disfarçar sua nacionalidade: 
"As mulheres espanholas odeiam a gente. É um horror, pensam que estamos sempre prontas para roubar o homem delas. Dá para perceber que o olhar delas muda e o tratamento também quando percebem que sou brasileira" (Morea, 28 anos, brasileira).

Para justificar sua oposição em relação às mulheres espanholas, as brasileiras produzem uma estrutura de discurso atribuindo-lhes as características de frias, conservadoras sexualmente, masculinizadas, desleixadas, grosseiras, egoístas e autoritárias. Assim, constroem um estereótipo feminino espanhol ao avesso de si mesmas, consideradas como quentes, liberadas sexualmente, femininas, bonitas, generosas e doces. $\bigcirc$ trecho que se segue é exemplar da polaridade estereotipada que é estabelecida pelas brasileiras em relação às espanholas, a fim de encontrar brechas de poder:

As mulheres espanholas não gostam das brasileiras. Odeiam. Odeiam, porque é inveja. Mas a diferença, aqui, é a seguinte: as espanholas, elas estudam. É a carreira em primeiro plano, são elas em primeiro lugar. Nós, brasileiras, não, né? Primeiro, vem o marido, filho, que estão sempre na frente, né? Elas são assim: eu, eu, eu e eu, e, por último, o meu marido, o meu filho, o meu carro. Primeiro, sou eu, minha vida, a minha profissão. Por isso que elas não se casam, elas não têm namorado, elas se casam com trinta e poucos anos, elas têm filho com quarenta anos, sabe? [...] $\bigcirc$ que acontece com as espanholas é o seguinte: elas não são carinhosas como a gente. Elas são muito, muito antiquadas, então, quando vão ter relação, não fazem um boquete. Não podem nem cogitar a possibilidade de fazer sexo não convencional, sabe? Fazem sexo uma vez por mês. Elas têm medo de perder o marido para nós. Mas, também, quem manda elas serem frias e não segurarem o homem delas, não é? Eu não vou na casa delas buscar o homem delas. São eles que vêm aqui atrás de mim (Electra, 26 anos, brasileira).

Os estereótipos produzidos pelas mulheres prostitutas brasileiras sobre as mulheres espanholas é uma forma de simultaneamente assimilar as representações hegemônicas sobre si mesmas e subvertê-las, usando-as como ferramentas de poder, como afirmam Aparício e Chávez-Silverman (1997) e De la Peña et al. (2009). Se a sociedade espanhola atribui pejorativamente às latinas a hipersexualidade, as brasileiras convertem essa mesma característica em vantagem no mercado sexual, ao mesmo tempo em que devem desvalorizar a sexualidade das mulheres espanholas.

Além disso, os atributos das representações das brasileiras em relação às espanholas justifica a clientela da prostituição. Os homens espanhóis são considerados pelas prostitutas brasileiras, vítimas de suas mulheres frias, arrogantes, autoritárias que precisam suprir suas carências e fantasias sexuais. Há a criação de um discurso que opões homem/mulher espanhóis nas representações das brasileiras, criando um binômio do homem devasso/emotivo/carente e mulher conservadora/racional/egoísta.

É na posição de complementaridade do homem espanhol que a mulher brasileira se justifica naquela sociedade. Entretanto, como clientes, os homens espanhóis devem ainda ser inferiorizados em relação ao poder de sedução das mulheres brasileiras, para que elas possam constituir a representação de uma posição de poder na relação entre prostituta-cliente. As 
brasileiras julgam que correspondem a uma lacuna de papel de gênero não cumprida pelas espanholas e, portanto, elas são as culpadas de seus maridos procurarem os serviços de prostituição, já que as espanholas não cumprem o papel social esperado pelos maridos.

\section{Considerações finais}

Argumentou-se aqui que, apesar de a tropicalização hegemônica produzida sobre as mulheres brasileiras estabelecer um discurso que exotiza sua corporeidade e sexualidade, elas reconhecem as estruturas de poder de que fazem parte e são capazes de encontrar suas fissuras para agir contra os processos de marginalização.

Uma das mais marcantes fissuras do poder hegemônico reconhecida pelas mulheres brasileiras profissionais do sexo é a organização e distribuição de recursos eróticos na sociedade espanhola. Os estereótipos que associam a brasilidade à hipersexualidade são amplamente usados pelas mulheres brasileiras profissionais do sexo no processo de competição da atividade comercial sexual. $\bigcirc$ reconhecimento dessa organização transforma-se em ferramenta para subverter o significado dos atributos que sustentam as representações sobre sua sexualidade e corporeidade. Produzem alianças com sujeitos hegemônicos por meio da conquista e do uso de recursos eróticos com os homens e oposições nas relações com as mulheres espanholas. As brasileiras profissionais do sexo estabelecem jogos interseccionais, escondendo ou exagerando sua "brasilidade" de acordo com as interações e os lugares que consideram vantajosos ou desvantajosos para conquistar poder. Nesse sentido, a tropicalização não tem um eixo linear e oposicional entre colonizadores e colonizados. As tensões que as mulheres brasileiras provocam na sociedade espanhola mostram que há um processo de inevitável tropicalização daquela sociedade. Ela se faz a partir de inúmeras configurações de relações de poder, envolvendo o jogo de interseções entre diferentes categorias identitárias promovidos pelos sujeitos em interação.

\section{Referências}

APARÍCIO, F. R.; CHÁVEZ-SILVERMAN, S. (Ed.). Tropicalizations: Transcultural Representations of Latinidad. New Hampshire: Dartmouth/University Press of New England, 1997.

BARDIN, L. Análise de Conteúdo. Lisboa: Edições 70, 1977.

BHABHA, H. Nation and Narration. London: Routledge, 1990.

BROWN, M. Gender and sexuality I: Intersectional anxieties. Progress in Human Geography, v. 36, n. 4, p. 541-550, 2012.

CRENSHAW, K. W. Mapping the margins: intersectionality, identity politics, and violence against women of color. Stanford Law Review, v. 43, n. 6, p. 1241-1299, 1991.

DANIELSON, M. T. Homecoming Queers: Desire and Difference in Chicana Latina Cultural Production. New Brunswick/New Jersey/London: Rutgers University Press, 2009.

DAVIS, K. Intersectionality as Buzzword: A Sociology of Science Perspective on What Makes a Feminist Theory Successful. Feminist Theory, v. 9, n. 1, p. 67-85, 2009. 
DE LA PEÑA, T. et al. Complicating Community. In: DANIELSON, M. T. (Ed.). Homecoming Queers: Desire and Difference in Chicana Latina Cultural Production. London: Rutgers University Press, 2009. p. 92-120.

ECHEZARRIETA, V. S.; LEYVA, M. J. S. Latinoamericanas en España: encarnación de un estereotipo ambivalente. In: RODRIGUE, I.; MARTÍNEZ, J. (Ed.). Postcolonialidades históricas: (in)visibilidades hispanoamericanas/colonialismos ibéricos. Barcelona: Anthropos, 2008. p. 169-186.

FERNANDES, D.; NUNAN, C. O imigrante brasileiro na Espanha: perfil e situação de vida em Madrid. In: ENCONTRO NACIONAL DE ESTUDOS POPULACIONAIS, 2008, Belo Horizonte. Anais... Belo Horizonte, 29 set. 3 out. 2008.

FOCUS, n. 565, p. 116-117, ago. 2010.

FONSECA, C. Afinal, o que é que a mulher brasileira tem... que nós não temos? Activa, 31 jul. 2011. Disponível em: <http://activa.sapo.pt/sexo/2011-07-31-afinal-o-que-e-que-a-mulher-brasileira-tem...-que-nos-nao-temos>. Acesso em: 10 mar. 2016.

GREEN, A. I. The Social Organization of Desire: The Sexual Fields Approach. Sociological Theory, v. 26, n. 1, p. 25-50, 2008.

GRUPO DAVIDA. Prostitutas, "traficadas" e pânicos morais: uma análise da produção de fatos em pesquisas sobre o "tráfico de seres humanos". Cadernos Pagu, v. 25, p. 153-184, 2005.

HOOKS, B. Marginality as a site of resistence. In: FERGUSON, R. et al. Out there: marginalization and contemporary cultures. Cambridge, MA: MIT Press, 1990. p. 241-243.

HYNES, H. P.; RAYMOND, J. G. Put in Harm's Way: The Neglected Health Consequences of Sex Trafficking in the United States. In: SILLIMAN, J.; BHATTACHARJEE, A. Policing the National Body: Race, Gender and Criminalization. Cambridge, MA: South End Press, 2002. p. 197-230.

INFANTE, A. Espanhóis preferem noivas brasileiras entre as estrangeiras, diz pesquisa. BBC, 16 abr. 2009. Disponível em: <http://www.bbc.co.uk/portuguese/noticias/2009/04/090416_espanahabrasileiras_fp.shtml>. Acesso em: 10 mar. 2016.

KEMPADOO, K.; SANGHERA, J.; PATTANAIK, B. Trafficking and prostitution reconsidered: new perspectives on migration, sex work, and human rights. London: Paradigm, 2005.

MASANET, E.; PADILLA, B. La inmigración brasileña en Portugal y España ¿Sistema migratório Ibérico? OBETS: Revista de Ciencias Sociales, v. 5, n. 1, p. 49-86, 2010.

McCALL, L. The Complexity of Intersectionality. Signs: Journal of Women, Culture and Society, v. 30, n. 3, p. 1771-1800, 2005.

McDOWELL, L. Thinking through Work: Complex Inequalities, Constructions of Difference and Trans-National Migrants. Progress in Human Geography, v. 32, n. 4, p. 491-507, 2008. 
NASH, J. Re-thinking Intersectionality. Feminist Review, v. 89, p. 1-15, 2008.

PELÚCIO, L. Amores perros: sexo, paixão e dinheiro na relação entre espanhóis e travestis brasileiras no mercado transnacional do sexo. In: PISCITELLI, A.; OLIVAR, J. M. N.; ASSIS, G. O. Gênero, sexo, amor e dinheiro: mobilidades transnacionais envolvendo o Brasil. Campinas: Pagu/Unicamp, 2012. p. 185-124.

Corpos indóceis: a gramática erótica do sexo transnacional e as travestis que desafiam fronteiras. In: SOUZA, L. A. F; SABATINE, T. T.; MAGALHÃES, B. R. Michel Foucault: sexualidade, corpo e direito. São Paulo: Oficina Universitária/Cultura Acadêmica, 2011. p. 105-132.

Erótica, exótica e travesti: nacionalidade e corporalidade no jogo das identidades no mercado transnacional do sexo. In: CASTRO, A. L. Cultura contemporânea, identidades e sociabilidades: olhares sobre corpo, mídia e novas tecnologias. São Paulo: Cultura Acadêmica, 2010. p. 197-214.

PISCITELLI, A. Tránsitos: circulación de brasileñas en el ámbito de la transnacionalización de los mercados sexual y matrimonial. Horizontes Antropológicos, v. 31, p. 131-137, 2009.

. Brasileiras na indústria transnacional do sexo. Nuevo Mundo - Mundos Nuevos, v. 7 , p. 20, 12 mar. 2007. Disponível em: <http://nuevomundo.revues.org/3744>. Acesso em: 3 mar. 2016.

Sujeição ou subversão? Migrantes brasileiras na indústria do sexo na Espanha. História \& Perspectivas, v. 1, n. 35, p. 13-55, 2006.

PISCITELLI, A.; ASSIS, G. O.; OLIVAR, J. M. N. (Ed.). Gênero, sexo, afetos e dinheiro: mobilidades transnacionais envolvendo o Brasil. Campinas, SP: Unicamp/Pagu, 2011.

PRATT, M. L. Arts of the contact zone. Profession, v. 91, p. 33-40, 1991.

SAID, E. Orientalism. New York: Vintage, 1979.

SÁNCHEZ, R. On a Critical Realist Theory of Identity. In: ALCOFF, L. M. et al. Identity Politics Reconsidered. New York: Palgrave, 2006. p. 31-52.

SCHAUER, E.; WHEATON, E. M. Sex Trafficking Into The United States: A Literature Review. Criminal Justice Review, v. 31, n. 2, p. 146-169, June 2006.

SPIVAK, G. Can the subaltern speak? In: NELSON, C.; GROSSBERG, L. Marxism and the interpretation of culture. Basingstoke: Macmillan, 1988. p. 271-313.

VALENTINE, G. Theorizing and Researching Intersectionality: A Challenge for Feminist Geography. The Professional Geographer, v. 59, n. 1, p. 10-21, 2007.

WOOK. Sinopse do livro Os segredos das mulheres brasileiras. Disponível em: $<$ http://www. wook.pt/ficha/os-segredos-das-mulheres-brasileiras/a/id/8971693 2. Acesso em: 10 mar. 2016. 